\title{
Pengaruh Store Atmosphere dan Experiential Marketing Terhadap Keputusan Pembelian Di Kopi Daong Pancawati
}

\author{
Achmad Imam Tantowi dan Anton Widio Pratomo \\ Program Studi Manajemen, Institut Bisnis dan Informatika Kesatuan \\ E-Mail: antonwidiopratomo@stiekesatuan.ac.id
}

\section{ABSTRACT}

This study aims to find out: (1) How is the influence of Store Atmosphere on purchasing decisions (2) How is the influence of Experiential Marketing on Purchasing Decisions. (3) How is the influence of Store Atmosphere and Experiential Marketing on Purchasing Decisions. The total sample of 140 respondents using the Hair formula. The data used are primary data derived from answers to questionnaires. Data processing using Statistical Package For Social Science (SPSS 25) analysis with multiple regression analysis methods, hypothesis testing, and ftest. The results of this study are as follows: (1) Store Atmosphere has a positive and significant effect on purchasing decisions in Daong Pancawati coffee with a multiple regression value of 0.353 and has a significant value of 0,000. (2) Experiential Marketing has a positive and significant effect on purchasing decisions in Daong Pancawati Coffee with a multiple regression value of 0.444 and has a significant value of 0,000. (3) Store Atmosphere and Experiential Marketing have a positive and significant effect on purchasing decisions in Daong coffee with a calculated $F$ value of 108.153 and is greater than the $f$ table of 3.06 and has a significant value of 0,000.

Keywords: Store Atmosphere, Experiential Marketing and Purchasing Decisions
Submitted: MARET 2020

Accepted: JULI 2020

\begin{abstract}
ABSTRAK
Penelitian ini bertujuan untuk mengetahui: (1) Bagaimana pengrauh Store Atmosphere terhadap keputusan pembelian (2) Bagaimana pengaruh Experiential Marketing terhadap Keputusan Pembelian. (3) Bagaimana pengaruh Store Atmosphere dan Experiential Marketing terhadap Keputusan Pembelian. Jumlah sampel sebanyak 140 responden dengan menggunakan rumus Hair. Data yang digunakan merupakan data primer yang berasal dari jawaban kuesioner. Pengolahan data menggunakan analisis Statistical Package For Social Science (SPSS 25) dengan metode analisis regresi berganda, uji hipotesis, dan uji f. Hasil penelitian ini sebagai berikut: (1) Store Atmosphere berpengaruh positif dan signifikan terhadap keputusan pembelian di kopi daong pancawati dengan nilai regresi berganda sebesar 0,353 dan memiliki nilai signifikan terhadap 0,000. (2) Experiential Marketing berpengaruh positif dan signifikan terhadap keputusan pembelian di Kopi Daong Pancawati dengan niliai regresi berganda sebesar 0,444 dan memiliki nilai signifikan terhadap 0,000. (3) Store Atmosphere dan Experiential Marketing berpengaruh positif dan signifikan terhadap keputusan pembelian di kopi daong dengan nilai $\mathrm{F}$ hitung sebesar 108,153 dan lebih besar dibandingkan dari f tabel 3,06 dan memiliki nilai signifikan sebesar 0,000 .
\end{abstract}

Kata Kunci: Store Atmosphere, Experiential Marketing dan Keputusan Pembelian

\section{JIMKES}


Customer Buying

Decision and

Experiential Mktg

\section{PENDAHULUAN}

Kota Bogor yang dikenal sebagai destinasi wisata yang cukup romantis dan berhawa sejuk telah memunculkan kreatifitas aneka wisata yang begitu luar biasa menciptakan suasana betah dan nyaman yang akan membuat seseorang merasa lebih ingin lama tinggal di kota bogor bagi wisatawan khususnya, membuat orang-orang yang bergerak di belakang dunia pariwisata bogor menciptakan tempat-tempat wisata di bogor yang eksotis dan juga menarik, termasuk salah satunya adalah berbagai kedai kopi atau coffee shop yang banyak sekali dan mudah ditemukan di segala penjuru Bogor. Kehadiran banyak tempat ngopi di kota bogor saat ini, seperti mau memberi gambaran kepada wisatawan bagaimana cara menikmati suasana kota bogor yang indah, romantis, nyaman dan pula berhawa sejuk dengan cara unik menikmati secangkir kopi dengan beragam aneka rasa, baik dinikmati secara bersama-sama dengan keluarga, teman, kolega bisnis, pasangan atau bahkan sendirian dengan rasa nyaman.

Saat ini, sebagian besar tanaman kopi yang di budidayakan di Indonesia adalah kopi robusta $(90 \%)$ dan sisanya kopi arabika. Penanaman kopi di Indonesia dimulai tahun 1696 dengan menggunakan jenis kopi arabika. Namun, penanaman jenis kopi ini kurang berhasil, tahun 1699 pemerintah Hindia Belanda mendatangkan lagi kopi arabika, kemudian berkembang dengan baik di Pulau Jawa. Kopi arabika yang dikenal sebagai kopi jawa (java coffee) tersebut memiliki kualitas yang sangat baik dan merupakan komoditas ekspor penting selama lebih dari 100 tahun. Adapun hal lain yang mendorong masuknya kopi robusta ke Indonesia adalah pembelian benih robusta oleh perusahaan 12 perkebunan yang bernama "Cultuur Mij. Soember Agoeng" tahun 1900 dari I'Horticule Coloniale yang berkedudukan di Brussel. Benih-benih untuk menghasilkan bibit tersebut di datangkan dari Kongo Belgia (sekarang Zaire) yang terletak di Afrika Barat. Tepat pada tanggal 10 September 1900 bibit-bibit kopi robusta diterima di Kebun Soember Agoeng. Perusahaan perkebunan tersebut berkantor di kota Gravenhage di Belanda dan mengelola perkebunan Soember Agoeng, Wringin Anom, dan Kali Bakar yang berlokasi di daerah dampit, sekitar $40 \mathrm{~km}$ dari kota Malang arah tenggara. Upaya memasukkan kopi robusta ke Indonesia juga dilakukan oleh gabungan pengusaha perkebunan di wilayah Kediri (Kedirische Landbouw Vereniging) pada tahun 1901. Selain itu, Pemerintah Hindia Belanda pada tahun tersebut juga memasukkan kopi robusta ke Kebun Percobaan milik Pemerintah Hindia Belanda (Governement Proeftuin) di Bangelan dekat Malang untuk keperluan penelitian.

Di Indonesia budaya minum kopi sendiri sudah berlangsung lama, banyak orang menikmati secangkir kopi di warung-warung kopi pinggir jalan dengan harga yang relatif murah dengan kisaran harga Rp.3.000 - Rp.5.000. Namun seiring dengan perkembangan zaman, kopi dapat dinikmati di kedai kopi yang lebih modern dengan menawarkan konsep yang berbeda. Menurut berita yang diterbitkan oleh AEKI-AICE (Asosiasi Eksportir dan Industri Kopi Indonesia), kopi di Indonesia dalam 10 tahun terakhir terus bergairah dengan semakin bertambah dan meningkatnya produksi kopi olahan, dan semakin suburnya cafe dan coffee shop di kota-kota besar. Data yang dikeluarkan oleh AEKI-AICE di bawah ini menunjukkan konsumsi kopi di Indonesia terus meningkat dari tahun 2010 sampai perkiraannya pada tahun 2016 mendatang.

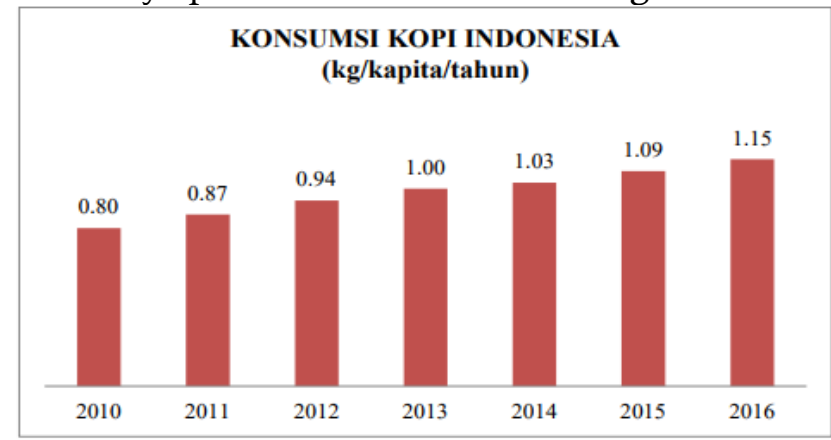

Gambar 1. Tingkat Konsumsi Kopi Di Indonesia

Sumber : www.aeki-aice.org 
Berdasarkan gambar 1.1 diatas dijelaskan bahwa konsumsi kopi di Indonesia dari tahun 2010 sebesar 0.80 dan mengalami kenaikan hingga tahun 2016 sebesar 1.15. Di kota Bogor ini sendiri sangat banyak sekali pelaku bisnis yang melirik usaha coffee shop, Persaingan coffee shop di kota bogor semakin terasa ketika melihat kembali banyaknya coffee shop yang tersebar di bogor. Mulai dari coffee shop kecil hingga yang berskala besar ada di kota bogor. Keadaan ini membuat persaingan coffee shop semakin ketat, berbagai macam cara dilakukan pemilik untuk menjadikan coffee shop nya manjadi yang terbaik di kota Bogor. Salah satu cara yang digunakan pemilik untuk membuat coffee shop nya ramai oleh pelanggan adalah dengan membuat suasana toko kopi sebaik dan senyaman mungkin. Semua coffee shop mempunyai keunikan dan ciri khas masing-masing. Coffee shop tersebut berlomba-lomba untuk berinovasi dan menciptakan keunggulan yang berbeda-beda. Keunggulan tersebut dapat dilihat dari makanan dan minuman yang disajikan, harga yang terjangkau, lokasi dan suasana tempat dan nyaman atau juga dapat dari hal-hal pendukung seperti live music dan hotspot bahkan ada pula coffee shop yang memberi kejutan kepada pelanggan dengan adanya wahana-wahana agar pelanggan dapat bermain dan berlibur pula.

Salah satu Coffee Shop di Bogor yang saat ini menjadi pilihan sebagai tempat berkumpulnya semua generasi muda bahkan tak jarang mereka Bersama keluarga sembari bercengkrama dan memandangi indahnya alam yang begitu memanjakan mata.Kopi Daong berada di daerah Pancawati, Bogor, Jawa Barat. Kopi Daong mulai beroperasi dari pukul 10:00 hingga 22:00 WIB. Dengan maraknya kedai kopi kekinian dengan berbagai konsep menarik saat ini sudah mulai menjamur di kota bogor. Dengan konsep yang hampir sama, membuat para penikmat kopi jenuh dengan suasana yang ditawarkan. Namun sedikit berbeda dengan kopi daong yang terletak di kawasan Pancawati, Bogor.Kopi Daong menawarkan sensasi menikmati kopi dengan desain autentik di tengah hutan pinus. Kedai kopi ini didirikan oleh seorang pengusaha sukses bernama Alex Benyamin yang juga merupakan pemilik santa monica group. Nama daong sendiri diambil dari kata daun yang kemudian menjadi daong lantaran sang pemilik merupakan keturunan dari Manado. Berdiri pada 10 April 2019 lalu, Kopi Daong menyajikan sensasi unik yang jarang sekali ditemukan di kota-kota besar di Jakarta bahkan di daerah bogor sekalipun. Berada di tengah hutan pinus, untuk mencapai kopi daong sendiri membutuhkan sedikit usaha lantaran jalannya yang cukup sempit dan harus melewati perumahan warga sekitar. Bagi Pelanggan yang berasal dari Jadetabek, sebaiknya keluar pintu tol ciawi selatan agar lebih dekat dan mudah untuk mencapai lokasi ini. Perjalanan yang panjang dan membutuhkan sedikit usaha ini nantinya akan terbayar ketika para pelanggan sudah sampai dan memasuki kawasan daong. Lantaran berada di kaki gunung pangrango, bagi pelanggan yang tidak tahan akan hawa dingin, sebaiknya mempersiapkan jaket atau berpakaian sedikit tebal. Pasalnya, cuaca di kopi daong akan terasa semakin dingin jika malam telah tiba. Suasana romantis juga akan semakin terasa ketika malam tiba lantaran lampu-lampu yang menyinari kopi daong akan dihidupkan dan menerangi anda. Bahkan bisa dijadikan tempat foto yang sangat digemari kaum milenial kebanyakan. dan di kedai kopi daong ini ternyata tidak hanya menyuguhkan kopi dan pemandangan-pemandanganya yang indah saja, kopi daong pun memiliki wahana-wahana sederhana untuk dinikmati oleh para pelangganya, seperti: Skybike, Permadani Terbang, Tunggan Kuda, Spot berfoto Istana Mini dan Spot-Spot yang indah lainya untuk berfoto.

Dapat dilihat dari tabel 1.bahwa setidaknya terdapat sepuluh coffee shop yang ternama di kota bogor, namun tidak menggunakan suasana alam (hutan pinus) sebagai store atmosphere dan experientieal marketing sebagai strategi bisnis mereka untuk memanjakan konsumen dan memberikan suasana yang unik dan mengesankan kepada pelanggan. Kopi Daong didesain dengan tema outdoor dan autentic.
Customer Buying

Decision and

Experiential Mktg 
Customer Buying

Decision and Experiential Mktg

$\underline{68}$
Tabel 1. Daftar 6 Recommended coffe shop di Bogor

\begin{tabular}{|l|l|l|}
\hline No & Nama Coffe Shop & \multicolumn{1}{c|}{ Alamat } \\
\hline 1 & Awal Mula Coffee & $\begin{array}{l}\text { Kedai kopi ini beralamat di Jalan Bina Marga II, Bogor } \\
\text { Tengah }\end{array}$ \\
\hline 2 & Anthology Coffee & $\begin{array}{l}\text { Komplek Danau Teratai, Jl. MH. Thamrin, } \\
\text { RT.03/RW.08, Cijayanti, Kec. Babakan Madang, Bogor, } \\
\text { Jawa Barat 16810 }\end{array}$ \\
\hline 3 & Popolo Coffee & Jl. Loader No. 9, Bogor Timur, Bogor. Telp. 0811-1102-25. \\
\hline 4 & Cohere & $\begin{array}{l}\text { J1. Ciheuleut No. 21C, Bogor Timur, Bogor. Telp. 0812- } \\
\text { 8561-7084. }\end{array}$ \\
\hline 5 & Popolo & Jl. Loader No. 9, Bogor Timur, Bogor. Telp. 0811-1102-25. \\
\hline 6 & Ahora Coffee & $\begin{array}{l}\text { Jl. Ciheuleut No.7, RT.04/RW.11, Baranangsiang, Kec. } \\
\text { Bogor Tim., Kota Bogor, Jawa Barat 16143 }\end{array}$ \\
\hline
\end{tabular}

(Sumber: https://www.liputan6.com/lifestyle/read/3890751/6-rekomendasi-coffeeshop-di-bogor-yang-nyaman-untuk-hangout)

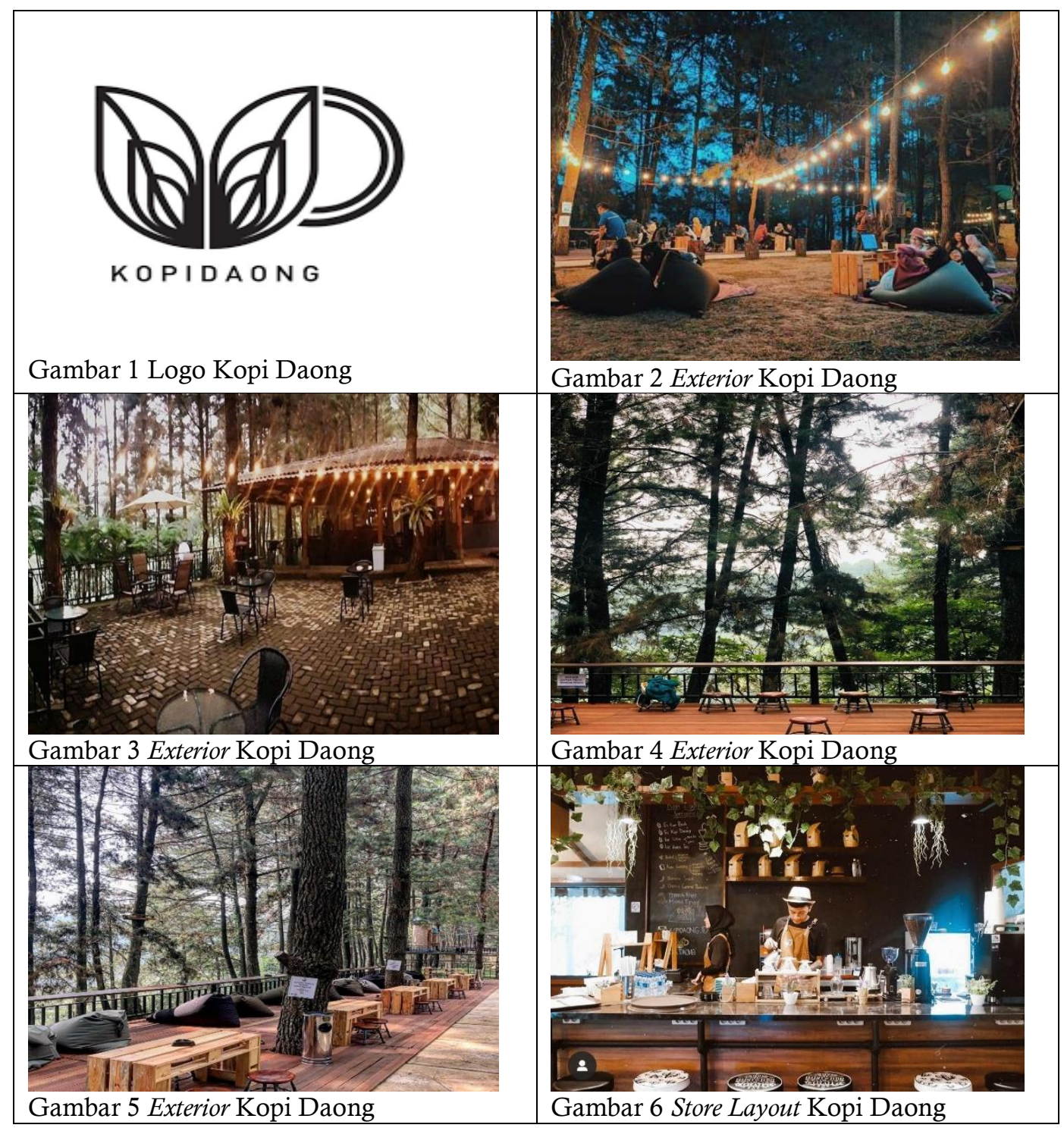




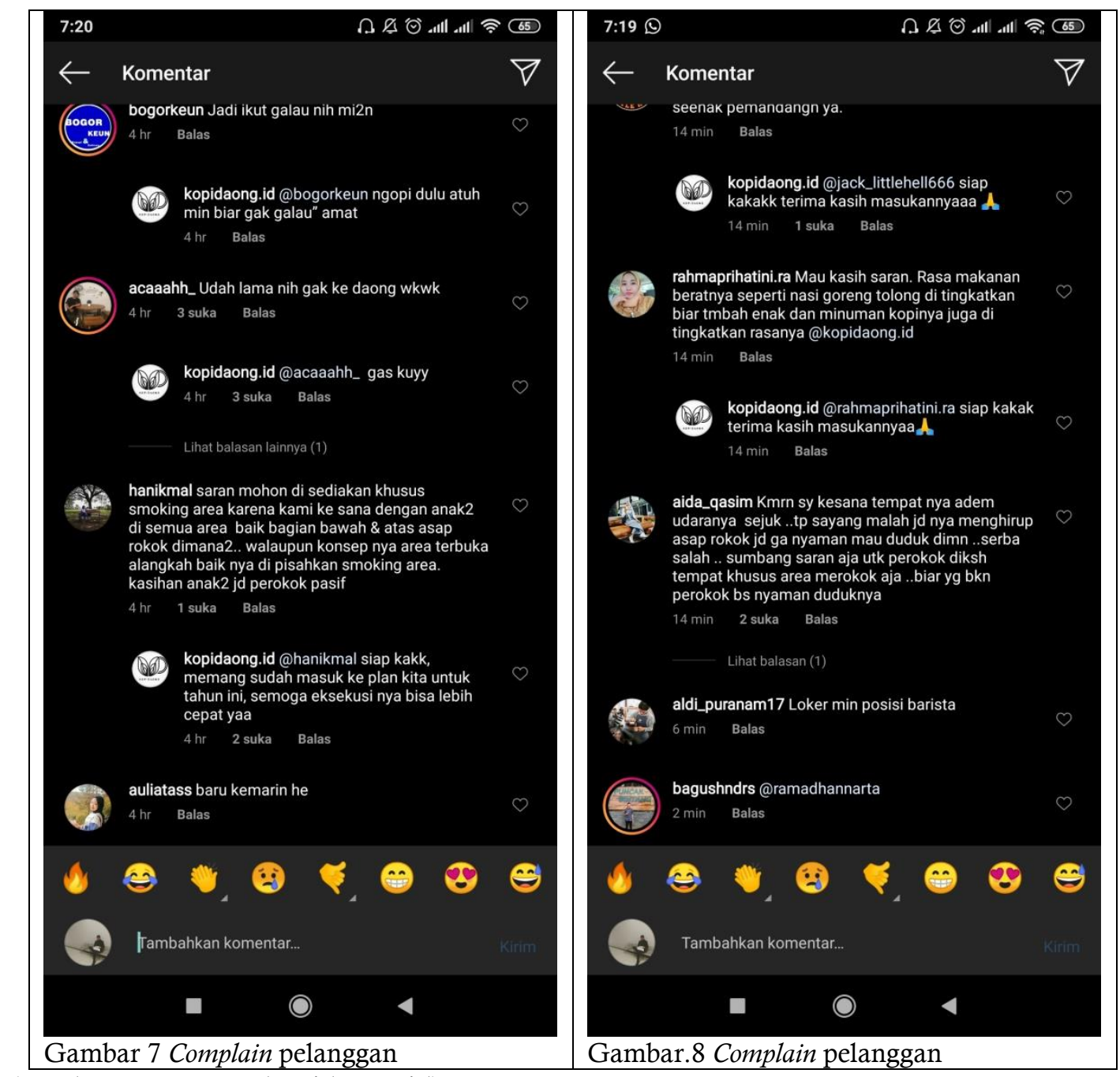

Customer Buying Decision and Experiential Mktg

(sumber: Instagram/kopidaong.id)

Pada era globalisasi dan urbanisasi saat ini, tuntutan konsumen akan lebih dinamis. Perusahaan dituntut untuk selalu mengikuti perkembangan zaman. Salah satu tuntutan yang harus dipenuhi perusahaan adalah dengan membuat atmosphere toko nya dengan baik dan semenarik mungkin. Tujuan nya adalah untuk mendapatkan loyalitas konsumen dan mampu mengarahkan keputusan pembelian konsumen yang nantinya akan sangat menentukan masa depan perusahaan. Oleh karena itu, sebuah perusahaan harus membuat konsep store atmosphere dan experiental marketing dengan baik. Sedangkan bagi penulis jika dilihat dari para review pelanggan kopi daong pada akun instagram official kopi daong terdapat beberapa masalah yang sering di komentari para pelanggan sebagai komentar yang negatif. Masalah terkait store atmosphere banyak pelanggan yang mengeluhkan tidak disediakanya atau di atur oleh pihak kopi daong mana tempat yang di peruntukan smoking area. Selain itu juga pada exterior café yang terlalu lebar tetapi tidak dapat tempat meneduh yang berdekatan jika hujan turun. Sehingga menyebabkan para pelanggan untuk berfikir ulang untuk dating ke kopi daong saat bogor musim hujan. Pada saat weekend tiba yang menyebabkan pelanggan datang ke café sangat banyak sedangkan pihak café tidak meningkatkan pelayanan menyebabkan beberapa pelanggan complain terkait meja makan yang tidak lekas di bersihkan sehabis di pakai pelanggan yang lain.

Sedangkan masalah terkait experiential marketing beberapa pelanggan mengeluhkan terkait rasa pada makanan nasi goreng dan kopi yang harus di tingkatkan, dan masalah lainya yang ada hubunganya dengan store atmosphere terkait tempat meneduh saat hujan turun akan menyebabkan pengalaman buruk kepada pelanggan yang makan di area exterior karena jauhnya tempat meneduh. Dan masih sama terkait masalah store atmosphere tentang smoking area banyak pelanggan yang tidak nyaman terutama bagi mereka yang 
Customer Buying

Decision and Experiential Mktg tidak merokok, karena kebanyakan pelanggan ingin menikmati suasana udara yang sejuk tetapi faktanya mereka masih terdampak asap rokok. pada saat weekend tiba pelanggan sangat banyak sedangkan pelayanan tidak di tingkatkan sehingga menyebabkan beberapa pelanggan complain terkait antrian yang panjang.

Berdasarkan uraian diatas, peneliti tertarik untuk melakukan penelitian guna mengetahui seberapa besar pengaruh store atmosphere, experiential marketing terhadap keputusan pembelian Di kopi daong pancawati sehingga perusahaan dapat melakukan perbaikan. Tujuan Penelitian ini berdasarkan rumusan masalah diatas adalah:

1. Untuk mengetahui pengaruh faktor Store Atmosphere terhadap keputusan pembelian di Kopi Daong Pancawati .

2. Untuk mengetahui pengaruh faktor Experiential Marketing terhadap keputusan pembelian di Kopi Daong .

3. Untuk mengetahui pengaruh faktor Store Atmosphere dan Experiential Marketing secara bersama-sama terhadap keputusan pembelian di kopi Daong.

Keputusan pembelian menurut (Tjiptono, 2008) sebuah proses dimana konsumen mengenal masalahnya, mencari informasi mengenai produk atau merek tertentu dan mengevaluasi seberapa baik masing-masing alternatif tersebut dapat memecahkan masalahnya, yang kemudian mengarah kepada keputusan pembelian. Dari Pengertian di atas dapat disimpulkan bahwa pengambilan keputusan konsumen adalah suatu proses pemilihan salah satu dari beberapa alternative penyelesaian masalah yang dikumpulkan oleh seorang konsumen, dan mewujudkanya dengan tindak lanjut yang nyata.Setelah proses tersebut, barulah konsumen itu dapat mengevaluasi pilihanya, dan menentukan sikap yang akan di ambil selanjutnya. Untuk membeli barang yang diambil konsumen merupakan kumpulan dari sejumlah keputusan. Menurut (Kotler \& Keller, 2012), tahap keputusan pembelian yang dilakukan konsumen, yaitu: pemilihan produk, pemilihan merek, pemilihan saluran pembelian, waktu pembelian dan cara pembayaran.

Menurut (Levy and Weitz, 2012) Store atmosphere adalah desain lingkungan seperti komunikasi visual, pencahayaan, warna, musik, dan aroma untuk mensimulasikan respon persepsi dan emosi pelanggan dan akhirnya mempengaruhi perilaku pembelian mereka.Pengertian Store Atmosphere menurut Kotler (2008) adalah suasan setiap gerai mempunyai tata letak fisik yang memudahkan atau menyulitkan untuk berputar-putar di dalamnya.setiap gerai mempunyai perbedaan yang berbeda-beda baik itu kotor, menarik, megah, dan suram. Suatu gerai harus membentuk suasana terencana yang yang sesuai dengan pasar sasarannyaa dan dapat menarik konsumen untuk membeli gerai tersebut. Store atmosphere memiliki elemen-elemen untuk membangun atmosfer toko yang ingin diciptakan. (Berman dan Evan, 2010) membagi empat kunci dalam elemen store atmosphere yaitu Exterior, general interior, store layout, dan interior displays. elemenstore atmosphere

Menurut Kottler dalam Maghnati at all (2012 :170). Experiential marketing dapat didefinisikan sebagai memori atau ingatan, juga pengalaman yang tertanam dalam pikiran juga perasaan seseorang. Hal ini dapat mempengaruhi instensitas pembelian dari konsumen melalui emosi yang ditimbulkan, juga menaikan nilai yang melekat pada produk atau merek itu sendiri. There are two type of marketing: traditional marketing and modern marketing. Modern marketing has overtaken traditional marketing due to the emphasizing on the concepts of customer experience and experiential marketing. Yang dapat diartikan adalah terdapat 2 jenis pemasaran: pemasaran secara traditional dan pemasaran secara modern. Pemasaran modern telah mengalahkan pemasaran secara traditional dengan menggunakan pendekatan terhadap pengalaman pelanggan dan pemasaran berdasarkan pengalaman. Setiap elemen-elemen diatas memiliki beberapa indikator, di dalam penelitian sebelumnya penulis menemukan beberapa indikator yang digunakan, walaupun ada juga yang tidak menggunakan indikator, melainkan menjadikan elemenelemen tersebut indikator. Menurut Novia, 2012 memilih indikator dari setiap elemen sebagai berikut: Sense experience, Feel experience, Think experience, Action experience, Relate experience 


\section{METODE PENELITIAN}

Penelitian dilakukan dengan menyebar kuesioner. Untuk mendapatkan data yang diperlukan, penulis melakukan penelitian dimulai pada bulan September 2019 sampai dengan Februari 2020. Lokasi Penelitian di Kota Bogor. Populasi Penelitian ini adalah masyarakat Kota Bogor yang pernah berkunjung, mengetahui dan melakukan keputusan pembelian di Kopi Daong Pancawati. Sampel Penelitian sebanyak 140 responden.Metode Analisis Data menggunakan Analisis regresi Berganda dengan sebelumnya melakukukan uji kualitas data secara bertahap mulai dari uji validitas dan reliabilitas lalu dilanjutkan dengan uji asumsi klasik yang meliputi uji normalitas, uji multikoliniearitas dan uji heteroskedastisitas. Hasil uji kualits data menunjukkan bahwa data telah memenuhi syarat untuk dilakukan uji regresi berganda.

Hipotesis Statistik yang diajukan dalam penelitian ini adalah ;

\section{Pengaruh Antara Store Atmosphere dengan Keputusan Pembelian}

$\mathrm{H} 0: \rho_{1}=0$, Store Atmosphere tidak mempunyai pengaruh dengan Keputusan Pembelian.

$\mathrm{H} 1: \rho_{1} \neq 0$, Store Atmosphere mempunyai pengaruh dengan Keputusan Pembelian.

Pengaruh Antara Experiential Marketing dengan Keputusan Pembelian

$\mathrm{H} 0: \rho_{1}=0$, Experiential Marketing tidak mempunyai pengaruh dengan Keputusan Pembelian.

$\mathrm{H} 1: \rho_{1} \neq 0$, Experiential Marketing mempunyai pengaruh dengan Keputusan Pembelian.

Pengaruh Antara Store Atmosphere dan Experiential Marketing dengan Keputusan Pembelian

H0: $\rho 1=\rho 2=\rho 3=0$, Store Atmosphere dan Experiential Marketing tidak mempunyai pengaruh dengan Keputusan Pembelian.

$\mathrm{H} 1: \rho 1 \neq \rho 2=\rho 3=0$, Store Atmosphere dan Experiential Marketing mempunyai pengaruh dengan Keputusan Pembelian.

\section{HASIL DAN PEMBAHASAN}

Profil Responden

Tabel 2 Distribusi Responden Berdasarkan Karakteristik Individu

\begin{tabular}{lcc}
\hline \multicolumn{1}{c}{ Karakteristik } & Frekuensi & Persen (\%) \\
\hline JENIS KELAMIN & & \\
Laki - Laki & 67 & 47,9 \\
Perempuan & 66 & 52,1 \\
USIA & & \\
15 s/d 20 tahun & 11 & 7,9 \\
20 s/d 29 tahun & 75 & 53,6 \\
30 s/d 34 tahun & 28 & 15,0 \\
35 s/d 39 tahun & 21 & 3,6 \\
> 40 Tahun & 5 & \\
PEKERJAAN & & 19,3 \\
pelajar / mahasiswa & 27 & 10,0 \\
pengajar / dosen & 14 & 50,7 \\
karyawan swasta & 71 & 16,4 \\
pegawai negeri & 23 & 3,6 \\
Wirausaha & 5 & 17,1 \\
PENGHASILAN & & 37,9 \\
$<$ 3.500.000 & 24 & 35,0 \\
3.500.001 s/d 5.000.000 & 53 & 10,0 \\
5.500.001 s/d 7.500.000 & 49 & \\
> 7.500.000 & 14 & \\
\hline
\end{tabular}

Sumber : Data Primer Output SPSS, 2020.
Customer Buying

Decision and

Experiential Mktg 
Customer Buying

Decision and Experiential Mktg

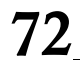

Profil responden atau karakteristik responden berguna untuk mengurai deskripsi identititas responden menurut sampel penelitian yang ditetapkan. Salah satu tujuan dengan dengan profil responden atau karakteristik responden adalah memberikan gambaran objek yang menjadi sampel dalam penelitian ini. Gambaran tentang profil responden atau karakterisitik responden diperoleh dari data diri yang terdapat pada identitas responden yang meliputi: jenis kelamin, umur, pendapatan atau uang saku perbulan, dan pekerjaan. Untuk memperjelas profil responden atau karakteristik responden yang dimaksud.

Berdasarkan tabel 2 bahwa responden laki-laki sebanyak 67 responden atau presentase $47,9 \%$. Dan perempuan sebanyak 73 responden atau presentase $52,1 \%$. Dengan data yang diperoleh peneliti mayoritas responden yang mendominasi adalah perempuan dibanding responden laki-laki. Berdasarkan tabel 2 data responden berdasarkan usia data yang diperoleh pada penelitian sebanyak 11 orang $(7,9 \%)$ berumur kurang dari $15 \mathrm{~s} / \mathrm{d} 20$ tahun, 75 orang $(53,6 \%)$ berumur antara $20-29$ tahun, 28 orang $(20,0 \%)$ berumur diantara lebih dari $30 \mathrm{~s} / \mathrm{d} 34$ tahun, 21 orang $(15,0 \%)$ berumur diantara lebih dari $35 \mathrm{~s} / \mathrm{d} 39$ Tahun, 5 orang $(3,6 \%)$ berumur diantara lebih dari 40 Tahun. Dengan data yang diperoleh peneliti mayoritas responden yang mendominasi berdasarkan umur adalah 20-29 tahun.

Berdasarkan tabel 2 data responden berdasarkan pekerjaan yang diperoleh pada penelitian dapat diketahui bahwa sebanyak 27 orang $(19,3 \%)$ responden sebagai pelajar/mahasiswa, 14 orang $(10,0 \%)$ responden sebagai pengajar atau dosen, 71 orang $(50,7 \%)$ responden sebagai karyawan swasta, 23 orang $(16,4 \%)$ responden sebagai pegawai negeri, dan 5 orang $(3,6 \%)$ responden sebagai wirausaha.Dengan ini menyatakan bahwa responden paling banyak yaitu sebagai karyawan swasta. Berdasarkan tabel 2 data responden berdasarkan pendapatan yang diperoleh dalam penelitian dapat diketahui bahwa sebanyak 24 orang $(17,1 \%)$ responden memiliki pendapatan kurang dari Rp. 3.500 .000 per bulan, 53 orang $(37,9 \%)$ responden memiliki pendapatan diantara Rp. 3.500 .001 - Rp. 5.000 .000 per bulan, 49 orang (35\%) responden memiliki pendapatan Rp. 5.500.001 - Rp. 7.500.000per bulan, 14 orang (10\%) responden memiliki pendapatan lebih dari Rp. 7.500.000 per bulan. Dengan ini menyatakan bahwa responden paling banyak memiliki pendapatan antara Rp. 3.500.001 - Rp. 5.000.000 per bulan.

\section{Analisis Persepsi Responden}

Untuk mengetahui tingkat persepsi responden tentang Store Atmosphere, Experiential Marketing dan Keputusan Pembelian di Kopi Daong Pancawati maka dilakukan analisa menggunakan analisis Rata-Rata terhadap hasil tanggapan responden pada masingmasing variabel dengan mengacu pada Skala Likert yang berbentuk ordinal: 5;4;3;2; dan 1 diperoleh Range $=(X m a k s i m u n-X m i n i m u m ~=5-1=4$, dan dibuat menjadi 3 kelas $:$ Tinggi ; Sedang ; dan Rendah. Maka interval dapat dibuat ; $4 / 3=1,33$ ).

Tabel 3 Persepsi Responden atas Indikator Variabel

\begin{tabular}{llll}
\hline No & Pertanyaan / Indikator & Rata-rata & Keterangan \\
\hline STORE ATMOSPHERE & $\begin{array}{l}\text { Store Atmosphere Kopi Daong memiliki Desain } \\
\text { bangunan yang unik dan mencerminkan suasanan } \\
\text { alam(General Exterior) }\end{array}$ & 3,60 & Tinggj \\
\hline $2 \begin{array}{l}\text { Store Atmosphere Kopi Daong memiliki Desain } \\
\text { bangunan interior yang menarik, unik, dan } \\
\text { rapih(General Interior) }\end{array}$ & 3,51 & Tinggi \\
\hline $3 \quad \begin{array}{l}\text { Store Atmosphere Kopi Daong memiliki Store } \\
\text { Layout yang tertata rapih dan membuat nyaman } \\
\text { (Store Layout) }\end{array}$ & 3,56 & Tinggi \\
\hline $\begin{array}{l}\text { Store Atmosphere Kopi Daong memiliki tempat } \\
\text { pemesanan yang terlihat menarik(Interior of } \\
\text { Purchase) }\end{array}$ & 3,62 & Tinggi \\
\hline
\end{tabular}




\begin{tabular}{llll}
\hline EXPERIENTIAL MARKETING & & \\
\hline 1 & $\begin{array}{l}\text { Experiential Marketing yang dimiliki Kopi Daong } \\
\text { terasa sejuk dan nyaman (Panca Indera) }\end{array}$ & 3,52 & Tinggi \\
\hline 2 & $\begin{array}{l}\text { Experiential Marketing pada Kopi Daong memiliki } \\
\text { pelayanan yang memuaskan (Perasaan) }\end{array}$ & 3,58 & Tinggi \\
\hline 3 & $\begin{array}{l}\text { Experiential Marketing pada Kopi Daong memiliki } \\
\text { promosi yang baik dan jelas (Berfikir) }\end{array}$ & 3,67 & Tinggi \\
\hline 4 & $\begin{array}{l}\text { Experiential Marketing pada Kopi Daong memiliki } \\
\text { metode pembayaran yang mudah(Aksi) }\end{array}$ & 3,85 & Tinggi \\
\hline 5 & $\begin{array}{l}\text { Experiential Marketing pada Kopi Daong memiliki } \\
\text { perlakuan pelayan yang sopan dan baik(relate) }\end{array}$ & 4,00 & Tinggi \\
\hline KEPUTUSAN PEMBELIAN & $\begin{array}{l}\text { Berkunjung ke kopi daong untuk memenuhi rasa } \\
\text { penasaran terhadap store kopi daong }\end{array}$ & 3,91 & Tinggi \\
\hline 2 & $\begin{array}{l}\text { Calon konsumen mencari informasi terkait kopi } \\
\text { daong sebelum berkunjung }\end{array}$ & 3,83 & Tinggi \\
\hline 3 & $\begin{array}{l}\text { Calon konsumen membandingkan store kopi } \\
\text { daong dengan competitor sejenisnya }\end{array}$ & 3,98 & Tinggi \\
\hline 4 & $\begin{array}{l}\text { Calon konsumen memutuskan untuk berkunjung } \\
\text { ke kopi daong untuk merasakan sensansi sesuai } \\
\text { suasana café kopi daong }\end{array}$ & 3,92 & Tinggi \\
\hline 5 & $\begin{array}{l}\text { Saya akan kembali berkunjung ke kopi daong dan } \\
\text { merekomendaskanya ke orang lain }\end{array}$ & 3,82 \\
\hline
\end{tabular}

Customer Buying

Decision and

Experiential Mktg

Sumber: Data Primer Diolah, 2020

\section{Analisis Korelasi}

Analisis korelasi antar variabel digunakan untuk mengetahui atau melihat adanya hubungan antara variabel Store Atmosphere, Experiential Marketing, dan Keputusan Pembelian, keeratan antar variabel hubungannya maka dari itu dilakukan analisis korelasi. Hasil dari korelasi yang dihasilkan oleh SPSS adalah koefisien korelasi yang menunjukkan kekuatan dan kelemahan dari suatu hubungan. Sedangkan untuk membuktikan ada tidaknya pengaruh antar variabel pada masing-masing variabel.

Tabel 4. Hasil Analisis Koefisein Korelasi

\section{Correlations}

\begin{tabular}{|c|c|c|c|c|}
\hline & & $\begin{array}{l}\text { Store } \\
\text { Atmosphere } \\
\text { (X1) }\end{array}$ & $\begin{array}{l}\text { Experiential } \\
\text { Marketing } \\
(X 2)\end{array}$ & $\begin{array}{l}\text { Keputusan } \\
\text { Pembelian } \\
\text { (Y) }\end{array}$ \\
\hline \multirow[t]{3}{*}{ Store Atmosphere (X1) } & $\begin{array}{l}\text { Pearson } \\
\text { Correlation }\end{array}$ & 1 &, $932^{* *}$ &, $763^{* *}$ \\
\hline & Sig. (2-tailed) & &, 000 &, 000 \\
\hline & $\mathrm{N}$ & 140 & 140 & 140 \\
\hline \multirow[t]{3}{*}{ Experiential Marketing (X2) } & $\begin{array}{l}\text { Pearson } \\
\text { Correlation }\end{array}$ &, $932^{* *}$ & 1 &, $774^{* *}$ \\
\hline & Sig. (2-tailed) & ,000 & & ,000 \\
\hline & $\mathrm{N}$ & 140 & 140 & 140 \\
\hline \multirow[t]{3}{*}{ Keputusan Pembelian (Y) } & $\begin{array}{l}\text { Pearson } \\
\text { Correlation }\end{array}$ &, $763^{* *}$ &, $774^{* *}$ & 1 \\
\hline & Sig. (2-tailed) &, 000 &, 000 & \\
\hline & $\mathrm{N}$ & 140 & 140 & 140 \\
\hline
\end{tabular}

**. Correlation is significant at the 0.01 level (2-tailed).

Berdasarkan Tabel 4. memperoleh hasil yang menunjukan bahwa variabel Store Atmosphere berkorelasi positif sebesar 0,932 terhadap variabel Experiential Marketing dapat disimpulkan kedua variabel mempunyai hubungan sedang, berdasarkan uji korelasi pearson diperoleh nilai 0,932 dengan tabel koefisien korelasi sebesar 0,80-1,00 dinyatakan 
Customer Buying Decision and Experiential Mktg memiliki hubungan yang signifikan positif sangat kuat Diperoleh pula hasil yang menunjukan bahwa variabel Store Atmosphere berkorelasi positif sebesar 0,763 terhadap variabel Keputusan Pembelian dapat disimpulkan kedua variabel mempunyai hubungan kuat, berdasarkan uji korelasi pearson diperoleh nilai 0,763 dengan tabel koefisien korelasi sebesar 0,60-0,799 dinyatakan memiliki hubungan yang signifikan positif kuat.

Dapat dilihat pula, pada Tabel 4. Terdapat hasil yang menunjukan bahwa variabel Experiential Marketing berkorelasi positif sebesar 0,932 terhadap variabel Store Atmosphere dapat disimpulkan kedua variabel mempunyai hubungan sangat kuat, berdasarkan uji korelasi pearson diperoleh nilai 0,932 dengan tabel koefisien korelasi sebesar $0,80=1,00$ dinyatakan memiliki hubungan yang signifikan positif sangat kuat. Tabel 4. pun menunjukan bahwa variabel Experiential Marketing berkorelasi positif sebesar 0,774 terhadap variabel Keputusan Pembelian dapat disimpulkan kedua variabel mempunyai hubungan kuat, berdasarkan uji korelasi pearson diperoleh nilai 0,774 dengan tabel koefisien korelasi sebesar 0,60-0,799 dinyatakan memiliki hubungan yang signifikan positif kuat.

\section{Analisis Koefisien Determinasi}

Koefisien determinasi $\left(\mathrm{R}^{2}\right)$ adalah satu ukuran yang digunakan untuk mengukur pengaruh variabel independen terhadap variasi variabel dependen, dengan $0<\mathrm{R}^{2}<1$. Sedangkan koefisien korelasi sederhan (r) merupakan akar koefisien determinasi.

Tabel 5. Koefisien Determinasi

\section{Model Summary}

\begin{tabular}{lllll}
\hline Model & $\mathrm{R}$ & $\mathrm{R}$ Square & Adjusted R Square & Std. Error of the Estimate \\
\hline 1 &, $782^{\mathrm{a}}$ &, 612 &, 607 & 2,524 \\
\hline
\end{tabular}

a. Predictors: (Constant), Experiential Marketing, Store Atmosphere

Sumber: Hasil Penelitian, 2020 (Pengolahan Data SPSS)

Berdasarkan Tabel 5 hasil output model summary dapat diartikan bahwa hubungan atau korelasi berganda pada seluruh variabel (Store Atmosphere, Experiential Marketing dan Keputusan Pembelian). memiliki kekuatan hubungan yang tinggi. Hal ini dilihat dari nilai koefisien korelasi berganda sebesar 0,782. Perolehan nilai koefisien determinasi r-square sebesar 61,2\% dapat diartikan bahwa variabel Store Atmosphere, Experiential Marketing dan keputusan pembelian mampu mempengaruhi atau menjelaskan keragaman (variabilitas). Nilai dan Keputusan Pembelian sebesar 61,2\% sedangkan sisanya sebesar (100\% - 61,2\% $=38,8 \%$ ) dipengaruhi oleh variabel lain yang tidak diteliti.

Uji Analisis Regresi Berganda

Analisis regresi berganda dalah alat untuk meramalkan nilai pengaruh dua variabel bebas atau lebih terhadap satu variabel terikat. Sebagai berikut :

Tabel 6 Hasil Uji Regresi Berganda

\begin{tabular}{|c|c|c|c|c|c|}
\hline \multicolumn{6}{|c|}{ Coefficients $^{\mathrm{a}}$} \\
\hline \multirow[b]{3}{*}{ Model } & \multirow{2}{*}{\multicolumn{2}{|c|}{$\begin{array}{l}\text { Unstandardized } \\
\text { Coefficients }\end{array}$}} & \multirow{2}{*}{\multicolumn{2}{|c|}{$\begin{array}{l}\text { Standardized } \\
\text { Coefficients }\end{array}$}} & \multirow[b]{3}{*}{ Sig. } \\
\hline & & & & & \\
\hline & $\mathrm{B}$ & Std. Error & Beta & $\mathrm{T}$ & \\
\hline (Constant) & 6,263 & 928 & & 6,751 &, 106 \\
\hline Store Atmosphere &, 353 & , 164 & ,317 & 2,155 &, 000 \\
\hline Experiential Marketing & ,444 & 137 &, 478 & 3,248 &, 000 \\
\hline
\end{tabular}

Dependent Variable: Keputusan Pembelian

Sumber: Hasil Penilitian, 2020 (Pengolahan Data SPSS)

Berdasarkan Tabel 6 dapat ditemukan persamaan regresi berganda untuk penelitian ini sebagai berikut :

$$
\hat{Y}=6,263+0,353 x_{1}+0,444 x_{2}+\text { error }
$$

Store Atmosphere $=$ Experiential Marketing $=0$, maka nilai dari keputusan pembelian sebesar 6,263 .

Jika Store Atmosphere (X1) naik (satu) satuan maka nilai Y akan meningkat sebesar 0,353 apabila variabel lain konstan. 
Jika Experiential Marketing (X2) naik (satu) satuan maka nilai Y akan meningkat sebesar 0,444 apabila variabel lain konstan.

\section{Uji Hipotesis Simultan (Uji F)}

Pengujian ini dilakukan untuk melihat ada atau tidaknya hubungan antara variabel Store Atmosphere dan Experiential Marketing (X) terhadap variabel Keputusan Pembelian (Y) secara simultan. Hasil analisis data yang peneliti lakukan dengan menggunakan program SPSS mendapatkan hasil, sebagai berikut:

Tabel 7 Hasil Uji Simultan (Uji F)

\begin{tabular}{|c|c|c|c|c|c|c|}
\hline \multicolumn{7}{|c|}{ Annova $^{a}$} \\
\hline Model & & \multicolumn{2}{|c|}{ Sum of SquaresDf } & Mean Square & $\mathrm{F}$ & Sig. \\
\hline & Regression & 1377,858 & 2 & 688,929 & 108,153 & $.000^{\mathrm{b}}$ \\
\hline & Residual & 872,685 & 137 & 6,370 & & \\
\hline & Total & 2250,543 & 139 & & & \\
\hline
\end{tabular}

a. Dependent Variable: Keputusan Pembelian

\section{Uji Hipotesis}

Uji ini dilakukan untuk menjawab hipotesis yang sudah dirumuskan pada bab sebelumnya, yaitu membuktikan hubungan antara teori dengan bukti empiris penelitian sebelumnya.

\begin{tabular}{|l|l|}
\hline \multicolumn{2}{|c|}{ Hipotesis Penelitian 1 } \\
\hline $\mathrm{H} 0: \beta 1=\beta 2=0$ & $\begin{array}{l}\text { Store Atmosphere tidak berpengaruh terhadap } \\
\text { Keputusan Pembelian }\end{array}$ \\
\hline $\mathrm{H} 1: \beta 1 \neq \beta 2 \neq 0$ & $\begin{array}{l}\text { Store Atmosphere berpengaruh terhadap Keputusan } \\
\text { Pembelian }\end{array}$ \\
\hline
\end{tabular}

Berdasarkan Tabel 6 mendapatkan nilai t-hitung untuk variabel adalah sebesar 2,155 yang nilainya lebih besar dari t-tabel $(\mathrm{df}=\mathrm{n}-\mathrm{k}-1=140-2-1, \alpha=5 \%=1,65)$ maka $\mathrm{H} 1$ diterima karena nilai t-hitung lebih besar dari t-tabel $(2,155>1,65)$ dan HO ditolak. Jadi, dapat dinyatakan bahwa Store Atmosphere berpengaruh positif dan signifikan terhadap Keputusan Pembelian atau bisa dikatakan bahwa hipotesis penelitian 1 diterima.

\begin{tabular}{|l|l|}
\hline \multicolumn{2}{|c|}{ Hipotesis Penelitian 2 } \\
\hline $\mathrm{H} 0: \beta 1=\beta 2=0$ & $\begin{array}{l}\text { Experiential Marketing tidak berpengaruh terhadap } \\
\text { Keputusan Pembelian }\end{array}$ \\
\hline $\mathrm{H} 1: \beta 1 \neq \beta 2 \neq 0$ & $\begin{array}{l}\text { Experiential Marketing berpengaruh terhadap } \\
\text { Keputusan Pembelian }\end{array}$ \\
\hline
\end{tabular}

Berdasarkan Tabel 6 mendapatkan nilai t-hitung untuk variabel adalah sebesar 3,248 yang nilainya lebih besar dari t-tabel $(\mathrm{df}=\mathrm{n}-\mathrm{k}-1=140-2-1, \alpha=5 \%=1,65)$ maka $\mathrm{H} 1$ diterima karena nilai t-hitung lebih besar dari t-tabel $(3,248>1,65)$ dan HO ditolak. Jadi, dapat dinyatakan bahwa Experiential Marketing berpengaruh positif dan signifikan terhadap Keputusan Pembelian atau bisa dikatakan bahwa hipotesis penelitian diterima.

\begin{tabular}{|l|l|}
\hline \multicolumn{2}{|l|}{ Hipotesis Penelitian 3 } \\
\hline $\mathrm{H} 0: \beta 1=\beta 2=0$ & $\begin{array}{l}\text { Store atmosphere dan Expriential Marketing secara } \\
\text { bersama-sama tidak memiliki pengaruh terhadap } \\
\text { Keputusan Pembelian }\end{array}$ \\
\hline $\mathrm{H} 1: \beta 1 \neq \beta 2 \neq 0$ & $\begin{array}{l}\text { Store atmosphere dan Expriential Marketing secara } \\
\text { bersama-sama memiliki pengaruh terhadap } \\
\text { Keputusan Pembelian }\end{array}$ \\
\hline
\end{tabular}

Berdasarkan Tabel 7 hubungan antara Store Atmosphere dan Experiential Marketing terhadap Keputusan Pembelian diperoleh f-hitung 108,153 dan lebih besar dari f-tabel $(\mathrm{df} 1=2, \mathrm{df} 2=138, \alpha=5 \%)=3,06$, dan didukung oleh nilai signifikansi sebesar 0,000 yang lebih kecil dari $(\alpha=5 \%)=0,05$ dengan demikian H0 ditolak dan H1 diterima maka Store Atmosphere (X1) dan Experiential Marketing secara bersama-sama memiliki pengaruh terhadap Keputusan Pembelian (Y), dengan demikian hipotesis penelitian 3 diterima
Customer Buying

Decision and

Experiential Mktg 
Customer Buying

Decision and Experiential Mktg

$\underline{76}$

\section{PENUTUP}

Kesimpulan penelitian ini adalah sebagai berikut:

1. Store Atmosphere memiliki pengaruh positif dan signifikan terhadap keputusan pembelian. Hal tersebut berdasarkan nilai regresi berganda sebesar 0,353 dan memilik nilai signifikansi sebesar 0,000. Hal ini berarti semakin tinggi Store Atmosphere akan semakin tinggi keputusan pembelian kopi daong.

2. Experiential Marketing memiliki pengaruh positif dan signifikan terhadap keputusan pembelian. hal tersebut berdasarkan nilai regresi berganda sebesar 0,328 dan memiliki nilai signifikansi sebesar 0,000. Hal ini berarti semakin tinggi Experiential Marketing akan semakin tinggi keputusan pembelian kopi daong.

3. Store Atmosphere dan Experiential Marketing secara bersama-sama memiliki pengaruh yang positif dan signifikan terhadap keputusan pembelian di Kopi Daong Pancawati. Hal tersebut berdasarkan uji simultan yang diperoleh atas variabel Store Atmosphere Dan Experiential Marketing yang memiliki hasil signifikan dan positif yang dilihat dari F-hitung 108,153 dan lebih besar dibandingkan nilai $F$ tabel 3,07 dengan nilai signifikan sebesar 0,000. Artinya semakin tinggi Store Atmosphere dan Experiential Marketing, maka keputusan pembelian di Kopi Daong Pancawati.

\section{DAFTAR PUSTAKA}

[1] Andreani, Fransisca. 2007. Pendekatan Pemasar dengan Experiential Marketing. Jurnal Manajemen Pemasaran, Vol. 2, No. 1-8. Universitas Petra

[2] Augusty, Ferdinand. 2006. Metode Penelitian Manajemen. Semarang: Badan Penerbit Universitas Diponegoro.

[3] Binangkitsari, L., 2018. The Influence of Brand Equity Elements on Purchase Decision and Its Imlication on Customer Loyalty.

[4] Cafeos Coffee Resources. 2014. Tetap Langsing Dengan Kopi. Di akses pada 14 Desember 2019. www.cafeoscafe.wordpress.com

[5] Dharmmesta, Basu Swastha., Handoko, T. Hani. 2012. Manajemen Pemasaran Analisis Perilaku Konsumen. Edisi Pertama. BPFE, Yogyakarta.

[6] Djanegara, M.S., Mulyani, S., Putra, D.M., Zahra, N.A.K. and Mauludina, M.A., 2018. The effect of institutionalization isomorphic pressures and the role of knowledge management on investment decisions of the accounting information systems. Polish Journal of Management Studies, 18.

[7] Eris Dwiyanti, Nurul Qomariah Dan Wenny Murtalining Tyas. 2018. Pengaruh Persepsi Kualitas, Nama Merek Dan Brand Awareness Terhadap Keputusan Pembelian. Universitas Muhammadiyah Jember. Jurnal Sains Manajemen Dan Bisnis Indonesia, Vol 8, No 2

[8] Fahimah. 2015. Pengaruh Store Atmosphere (Suasana Toko) Terhadap Keputusan Pembelian (Survei Pada Pengunjung Di Madam Wang Secret Garden Cafe Malang). Jurnal Administrasi Bisnis, Vol 28, No 2.

[9] Fredy Sugiman Dan Rika Mandasari. 2015. Pengaruh Store Atmosphere Terhadap Keputusan Pembelian Pada Sanctuary Di Surabaya. Jurnal Hospitality dan Manajemen Jasa, Vol 3, No 2.

[10] Gendalasari, G.G. and Triandi, T., 2018. Potret Kinerja UMKM Sepatu Di Bogor Dalam Berkompetisi Pada Perekonomian Di Indonesia. Jurnal Ilmiah Manajemen Kesatuan, 6(2), pp.102-108.

[11] Ghozali, Imam. 2009. "Aplikasi Analisis Multivariate dengan Program SPSS “. Semarang: UNDIP.

[12] Hasan, Ali. 2008. Marketing. Yogyakarta: Medpress.

[13] Hasan, Ali. 2013. Marketing dan Kasus-Kasus Pilihan, Yogyakarta, CAPS. (indikator experiential).

[14] Hendarsono, Gerson dan Sugiharto, Sugiono. 2013. Analisis Pengaruh Experiental Marketing Terhadap Minat Beli Ulang Konsumen Cafe Buntos 99 Sidoarjo. 
Jurnal Manajemen Pemasaran Universitas Kristen Petra, Vol.1 No.2 hal 1-8. diakses tanggal 2 Oktober 2013.

[15] Hidayat, L., Muktiadji, N. and Supriadi, Y., 2019. Pengaruh Pengetahuan Investasi Terhadap Minat Mahasiswa Berinvestasi Di Galeri Investasi Perguruan Tinggi. JASPT (Jurnal Analisis Sistem Pendidikan Tinggi Indonesia), 3(2), pp.63-70.

[16] Iriyadi, I., 2019. Prevention of Earnings Management through Audit Committee and Audit Quality in the Award-Winning and Non-Winning Companies. Journal of Accounting Research, Organization and Economics, 2(2), pp.155-169.

[17] Keren, K. and Sulistiono, S., 2019. Pengaruh Motivasi, Budaya, dan Sikap Konsumen Terhadap Keputusan Pembelian Produk Indomie. Jurnal Ilmiah Manajemen Kesatuan, 7(3), pp.319-324.

[18] Kopi Daong. 2019. Profil Instagram. diakses pada 14 Desember 2019. Instagram/kopidaong.id

[19] Kotler dan Keller 2012. Manajemen Pemasaran. Edisi 12 Jakarta: Erlangga.

[20] Kotler, Philip \& Keller, Kevin Lane. 2012. Marketing Management 14th edition. Harlow: PearsonEducation.

[21] Levy, Michael \& Weitz, Barton A. 2012. Reitailing Management (8thed.) New York, America: Mr. Graw-Hill/Irwin.

[22] Ling, T.S. and Pratomo, A.W., 2020. Pengaruh Brand Image, Persepsi Harga dan Word Of Mouth Terhadap Keputusan Pembelian Konsumen The Highland Park Resort Hotel Bogor. Jurnal Ilmiah Pariwisata Kesatuan, 1(1), pp.31-42.

[23] Maghnati, Farshad., Kwek Choon Ling dan Amir Nasermoadeli. 2012. Exploring the Relationship between Experiential Marketing and Experiential Value in the Smartphone Industry. International Business Research; Vol. 5, No. 11.

[24] Mowen, John C \& Michael Minor. 2002. Perilaku Konsumen, Edisi 5 Jilid 1, Jakarta: Erlangga.

[25] Munawar, A., Syarif, R. and Morita, M., 2019. Persepsi Mahasiswa Atas Galeri Investasi Perguruan Tinggi dan Pengaruhnya Terhadap Minat Berinvestasi. JAS-PT (Jurnal Analisis Sistem Pendidikan Tinggi Indonesia), 3(2), pp.89-96.

[26] Novia, Vivi. 2012. Pengaruh Experiential Marketing Terhadap Customer Loyalty Pada pelanggan Restoran Koki Sunda Di Pekanbaru. Jurnal Manajemen Universitas Riau 2012.

[27] Nuraini, A., Gendalasari, G.G. and Sastra, H., 2017. Studi Peningkatan Pertumbuhan dan Nilai Perusahaan Sektor Perkebunan Melalui Analisis Kebijakan Dividend an Profitabilitas. Jurnal Ilmiah Manajemen Kesatuan, 5(2), pp.074-079.

[28] Purba, J.H.V., Ratodi, M., Mulyana, M., Wahyoedi, S., Andriana, R., Shankar, K. and Nguyen, P.T., 2019. Prediction Model in Medical Science and Health Care. International Journal of Engineering and Advanced Technology, 8, pp.815-818.

[29] Purba, J.H.V., 2017. The analysis of European Union's vegetable oil consumption:" will the European Parliament Resolution Halt the Consumption of Crude Palm Oil in the European Union in the future?". International Journal of Applied Business and Economic Research, 15, p.19.

[30] Putu Elmira. 2019. 6 Rekomendasi Coffee Shop di Bogor yang Nyaman untuk Hangout. Di akses Pada 14 Desember 2019.

[31] Rizki Ramadhan, N. Rachma dan M. Hufron. 2019. Pengaruh Experiential Marketing Terhadap Loyalitas Pelanggan (Studi Kasus Pada Rambo Taichan Di Kota Malang). Jurnal Ilmiah Riset Manajemen, Vol 8, No 20.

[32] Sangadji, Etta Mamang \& Sopiah. 2013. Perilaku Konsumen - Pendekatan praktis disertai himunan Jurnal Penelitian. Yogyakarta: ANDI.

[33] Setiawan, B., Panduwangi, M. and Sumintono, B., 2018. A Rasch analysis of the community's preference for different attributes of Islamic banks in Indonesia. International Journal of Social Economics.

[34] Sudaryono, 2013 . Pengembangan Instrumen Penelitian Pendidikan. Yogyakarta: Graha Ilmu. 
Customer Buying Decision and Experiential Mktg

78
[35] Sugiyono, 2016 . Metode Penelitian Kuantitatif Kualitataif dan Kombinasi (Mixed Methods). Bandung: Alfabeta.

[36] Soedargo, B.P., 2019. Dampak Kualitas Pelayanan Terhadap Kepuasan Pasien Rawat Inap Peserta BPJS Kesehatan Di RS Melania Bogor. Jurnal Ilmiah Manajemen Kesatuan, 7(3), pp.295-302.

[37] Suharsono Syahputra, Anik Lestari Andjarwati. 2019. Pengaruh Kualitas Layanan dan Experiential Marketing terhadap Niat Berkunjung Ulang dengan Kepuasan sebagai Variabel Mediasi (Studi pada Pengunjung Wisata Edukasi Kampung Coklat Blitar). Universitas Negeri Surabaya. Jurnal Ilmu Manajemen, Vol 7, No 1.

[38] Wibowo, W. and Mekaniwati, A., 2020. Pengaruh Struktur Modal dan Kemampulabaan Terhadap Return Saham Perusahaan Properti dan Real Estate Yang Terdaftar di BEI Tahun 2013-2015. Jurnal Ilmiah Manajemen Kesatuan, 8(1), pp.19-28.

[39] Zuhdi, S., Rainanto, B.H. and Apriyani, D., 2020, May. Analysis of Co-Branding Strategy to Improve Company's Competitive Power (Case Study on Walls Selection Oreo). In 2nd International Seminar on Business, Economics, Social Science and Technology (ISBEST 2019) (pp. 146-149). Atlantis Press. 